\title{
A COMPUTER CENTER SURVEY:
}

\section{WHAT STUDENTS DON'T LIKE}

\author{
GARY P, FISHER \\ HAY-HUGGINS ACTUARIAL CONSULTANTS \\ PHILADELPHIA, PA
}

\section{INTRODUCTION}

The idea for a survey of users at the "Metro" University Computer Center grew out of personal observations made when using the facility in September 1980. Service times -- both to use a keypunch machine and to receive one's printed program -- seemed inordinately and uncomfortably long. Cramped and crowded waiting areas made these service delays even more unpleasant. The consultants on duty were sometimes nowhere in sight, sometimes besieged by long lines of of students, and usually, once one got an interview, unfriendly. Assuming that these experiences were not unusual, I hypothesized that lengthy service times and inadequate consulting might lead to dissatisfaction among users with the computer facilities.

A queueing study would have provided precise waiting times and queue lengths for computer center services, but my concern was the impact these factors have on user satisfaction. I anticipated that those segments of the user population with more limited access to the facilities -commuting students traveling 25 or more minutes from home -- would feel the waiting times more intensely. These students have less flexibility than "Metro" residents in choosing when to avoid those crowded periods that arise unexpectedly at the center. Long-distance commuters, I predicted, should therefore experience longer waits and rate the center's performance lower than their non-commuting counterparts.

METHODOLOGY

The Questionnaire

I devised for the pre-test a two-page, thirty-question self-administered survey which solicited demographic information, ratings of some services, average waits for turnover and keypunches, suggestions for improvement (more keypunches, longer hours, and so on), and user characteristics. These user characteristics included how of ten and at what times a student used the center and what languages he could program in. 
My sample of 40 computer center users consisted mostly of males $(67.5 \%)$, commuters $(72.5 \%)$, and either sophomores $(37.5 \%)$ or pre-juniors $(27.5 \%)$. Exactly half of the students travelled more than 25 minutes to reach the center. The relative absence of freshmen (7.5\%) and graduate students $(7.5 \%)$ from the sample is notable but not inexplicable. Few freshmen take computer courses because they must first satisfy curriculum requirements and course prerequisites; many graduate faculty (in business or library science, for example) encourage their students to use the facilities at a computer utility elsewhere.

The sample embraces a fairly sophisticated group of programmers: $70 \%$ report that they know more than one high-level or assembler language; $90 \%$ know Fortran; 55\% know languages other than PL/1, Fortran, or Cobol. Respondents used the center an average of 3 days and 8.5 hours during the week preceding the survey, which took place the week of February 8, 1981.

The 40 questionnaires were completed within two full days (Tuesday and Wednesday). Because most students did not answer questions that demanded a written response, I was unable to collect data on users' majors or the course that required them to use the center.

Index of Satisfaction

To measure fully a user's satisfaction with the computer facilities, I devised an index of satisfaction composed of the following responses:

\begin{tabular}{|c|c|}
\hline RESPONSE & VALUE \\
\hline $\begin{array}{l}\text { CENTER HOURS SHOULD NOT BE EXTENDED } \\
\text { BLANK CARDS ARE USUALLY AVAILABLE } \\
\text { CONSULTANTS ARE HELPFUL } \\
\text { CONSULTANTS ARE KNOWLEDGEABLE } \\
\text { KEYPUNCH INSTRUCTIONS ARE CLEAR AND MACHINE } \\
\text { IS EASY TO OPERATE } \\
\text { CARD READER INSTRUCTIONS ARE CLEAR AND MACHINE } \\
\text { IS EASY TO OPERATE } \\
\text { OPERATING HOURS ARE CONVENIENT } \\
\text { COMPUTER FACILITIES ARE ADEQUATE }\end{array}$ & 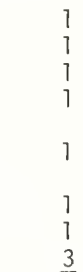 \\
\hline
\end{tabular}

$$
\text { TOTAL }=10
$$

Scores on the satisfaction index included all values from 0 to 10 with a median of 5 and an interquartile range of 3 . Individual scores were collapsed to create three degrees of user satisfaction, LOW (0-4), MODERATE (5-7), and HIGH (8-10) for crosstabulation and analysis. (TABLE 1.)

The index of satisfaction encompasses and enlarges upon the user's response to the question of the center's adequacy. Comprising a number of sources of user satisfaction -- ratings of consultants, readability of machine instructions and ease of machine operation, adequacy of operating hours -- the index gives a fuller, more objective picture of the user for 
crosstabuiations with demographic variables. In crosstabulations with service factors (turnover and keypunch waits, consultant ratings), the adequacy rating was principaliy used, since the satisfaction index included too many items unrelated to the problems under analysis.

Responses concerning waiting times were excluded from the index because the a priori determination of how long a waiting time must be before it equals 1 point on the index begs the question of this study.

\section{RESULTS}

The median score of 5 on the 10 point satisfaction index strongly suggests that services could be improved at the "Metro" Computer Center. $44.7 \%$ of the respondents rated the center not adequate, contributing to these low index scores. Students were also critical of the center's operating hours and consultarits. Although $74.4 \%$ said that the current operating hours were convenient, $64.7 \%$ would still 1 ike those hours extended. Consultants were rated as more helpful (70\% found them helpful) than knowledgeable $(62.5 \%)$. More positive ratings include: $93.9 \%$ thought that keypunch instructions were clear and the machine was easy to operate; $87.5 \%$ felt the same way about the card reader; $68.8 \%$ reported that an adequate supply of blank cards was usually avajlable.

To uncover those factors that might contribute to a user's low satisfaction score or rating of the center as not adequate, I crosstabulated demographic variables, user characteristics, and service factors with user satisfaction; and service factors with the rating of center adequacy.

Negative ratings of consultants (not helpful, not knowledgeable) and hiqh turnover times (over 75 minutes) were the service factors most strongly associated with a user's rating of the center as not adequate (TABLES 2-4). The avai?ability and waiting times for a keypunch, conversely, exhibited little or no relationship with the adequacy rating (TABLES 5-6).

All three of the service factors that were strongly associated with center inadequacy were only slightly less related to low user satisfaction (TABLES 7-9). Even though both consultant ratings did account for one point each in the index, one can not discount the strong association between user dissatisfaction and the belief that a consultant is not helpful or knowledgeable. On the other hand, only one item related to keypunching revealed any association with user satisfaction. Longer keypunch waits, contrary to expectations, tended to go along with high satisfaction scores (TABLES 10-11). Those students who spent the most hours at the center during the week of February 8 (though not necessarily the most days) reported lower satisfaction scores than other students (TABLE 12).

The strong associations of turnover time and the availability of helpful and knowledgeable consultants with user satisfaction and center adequacy suggest that difficulties in the running and debugging of computer programs, rather than their keypunching, greatly contribute to a student's rating of the center's performance. "Metro" computer center 
users appear to be goal-oriented. Unproductive moments spent waiting for programs to work prove more unsatisfactory than time spent on routine tasks (waiting for keypunches to become available). And the more hours a student spends at the center running, consulting about, and debugging his programs, the greater his dissatisfaction with services tends to be.

Independent demographic variables (sex, class, commuter or resident student) had little observed effect on user satisfaction. Students who travel 25 or more minutes to reach the center reported ratings and exhibited user habits mostly indistinguishable from other students. Contrary to expectations, the association between a student's travel time to the center and satisfaction score was weak and statisticaliy insignificant (TABLE 13). These long-distance commuters did not rate consultants appreciably lower than did other students: $71.4 \%$ to $68.8 \%$ helpful, $60 \%$ to $68.8 \%$ knowledgeable. They don't use the center more ( 7.8 to 8.1 hours per week) or at different hours. Ratings of center adequacy did not vary significantly when crosstabulated with travel time (TABLE 14).

Students who travel 25 or more minutes to the center, however, did tend to wait longer for keypunches to become available (TABLE 15), as expected. But longer waits for keypunches, as has been shown, do not lead to lower ratings of the center. It was in their attitudes toward current operating hours that these students were most distinctive. Only $57.9 \%$ of them, as opposed to $94.7 \%$ of the other students, found these hours convenient. Extending these operating hours, however, did not receive significantly more approval from long distance commuters $68.3 \%$ to $58.8 \%$. One must conclude from this data that problems incurred in the running and debugging of problems have a greater impact on a traveling student's rating of the center than do his scheduling problems and waits for keypunches.

\section{CONCLUSIONS}

While most students found that keypunches and cardreaders were easy to operate and that center hours were convenient for them, they were less affirmative in their ratings of consultants and the overall adequacy of the center. $44.7 \%$ thought that the facilities were not adequate; this contributed greatly to the median of 5 on the 10 point user satisfaction index. The unavailability of and long waits for keypunches did not, however, tend to lower user satisfaction. Rather, long job turnover times and low ratings of consultants strongly associated with an inadequate rating of the facility as well as with low satisfaction scores. It is not the waiting, then, but what you wait for that matters to users. Disturbances in the running and debugging of programs generate user dissatisfaction.

Given this goal-orientation of "Metro" computer users, efforts spen: on improving consulting services and reducing turnover times should have the greatest impact on improving computer center performance, as measured by its users. Employing more dispatchers and consultants would be more ameliorative than purchasing new keypunch machines. 
Table 1. User satisfaction index

Score

Frequency

Percent

$0-4$ LOW

16

40

$5-7$ MEDIUM 12

30

8 - $10 \mathrm{HIGH}$

$\frac{12}{40}$

$\frac{30}{100}$

Table 2. Center adequacy by averace turnover time

$$
\text { Average Turnover Time (Minutes) }
$$

Adequate

$$
0-15
$$

16 or more

Yes

$71 \%$

36

No

$\begin{array}{ll}\frac{29}{100 \%} & \frac{64}{100 \%} \\ N=17 & N=14\end{array}$

Table 3. Center adequacy by consultant knowledceability

\section{Consultants Are Knowledgeable}

Adequate Yes No

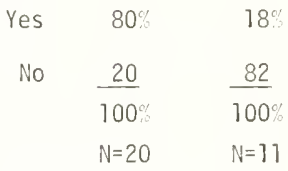

Table 4. Center adequacy by consultant helpfulness

Consultants Are Helpful

Adequate Yes No

$\begin{array}{llr}\text { Yes } & 76 \% & 25 \\ \text { No } & \frac{24}{100} & \frac{75}{100} \\ & N=21 & N=8\end{array}$


Table 5. Center adequacy by average wait for keypunch

\section{Average Wait (Minutes)}

\begin{tabular}{|c|c|c|c|}
\hline Adequate & $0-5$ & $6-10$ & $11-15$ \\
\hline Yes & $75 \%$ & $36 \%$ & $50 \%$ \\
\hline \multirow[t]{3}{*}{ No } & 25 & 64 & 50 \\
\hline & $100 \%$ & $100 \%$ & $100 \%$ \\
\hline & $N=4$ & $N=11$ & $N=4$ \\
\hline
\end{tabular}

Table 6. Center adequacy by availability of keypunches

Keypunches Are Available

$\begin{array}{rcc}\text { Adequate } & \text { Usual1y } & \text { Not Usual1y } \\ \text { Yes } & 36 \% & 71 \% \\ \text { No } & \frac{64}{100 \%} & \frac{29}{100 \%} \\ & N=28 & N=7\end{array}$

Table 7 . User satisfaction index by average turnover time Average Turnover Time (Minutes)

$\begin{array}{rcc}\text { Satisfaction } & 0-15: & 16 \text { or m } \\ \text { High } & 47 \% & 25 \% \\ \text { Medium } & 35 & 13 \\ \text { Low } & \frac{18}{100 \%} & \frac{62}{100 \%} \\ & N=17 & N=16\end{array}$

Table 8. User satisfaction index by consultant helpfulness Consultants Are Helpful

$\begin{array}{rcc}\text { Satisfaction } & \text { Yes } & \text { No } \\ \text { High } & 55 \% & 8 \% \\ \text { Medium } & 30 & 25 \\ \text { Low } & \frac{15}{100 \%} & \underline{67} \\ & 100 \% \\ & \mathrm{~N}=21 & \mathrm{~N}=9\end{array}$


Table 9. User satisfaction index by consultant knowledgeability Consultants Are Knowledgeable

Satisfaction

High

Medium

Low
Yes No

$55 \% \quad 8 \%$

30

25

$\begin{array}{ll}\frac{15}{100} & \frac{67}{100} \\ \mathrm{~N}=20 & \mathrm{~N}=12\end{array}$

Table 10. User satisfaction index by average wait for keypunch Average Wait for Keypunch (Minutes)

Satisfaction $\quad 0-5 \quad 6-10 \quad 11-15$

High $\quad 0 \% \quad 36^{\circ} \quad 50^{\circ}$

$\begin{array}{rccc}\text { Medium } & 20 & 27 & 25 \\ \text { Low } & \frac{80}{100} & \frac{36}{100} & \frac{25}{100} \\ & N=5 & \quad N=17 & N=4\end{array}$

Tabie 11. User satisfaction index by availability of keypunches Keypunches Are Available

Satisfaction Usually Not Usually

High 34 25:

Medium 32

25

Low

$\begin{array}{ll}\frac{34}{100} & \frac{50}{100} \\ N=29 & N=8\end{array}$


Table 12. User satisfaction index by hours spent in center Hours Spent in Center

$\begin{array}{rccc}\text { Satisfaction } & 0-5 & 6-10 & 11-20 \\ \text { High } & 56 \% & 15 \% & 9 \% \\ \text { Medium } & 25 & 31 & 36 \\ \text { Low } & \frac{19}{100 \%} & \frac{54}{100 \%} & \frac{55}{100 \%} \\ & N=16 & \mathrm{~N}=13 & \mathrm{~N}=11\end{array}$

Table 13. User satisfaction index by travel time to center Travel Time to Center (Minutes)

$\begin{array}{rcc}\text { Satisfaction } & 0-25 & 25+ \\ \text { High } & 32 \% & 30 \% \\ \text { Medium } & 42 & 20 \\ \text { Low } & \frac{26}{100 \%} & \frac{50}{100 \%} \\ & N=19 & N=20\end{array}$

Table 14. Center adequacy by travel time to center

$$
\text { Travel Time to Center (Minutes) }
$$

$\begin{array}{rrr}\text { Adequate } & 0-25 & 25 \div \\ \text { Yes } & 63 \% & 50 \% \\ \text { No } & \frac{37}{100 \%} & \frac{50}{100 \%} \\ & N=19 & N=18\end{array}$

Table 15. Average wait for keypunch by travel time to center Travel Time to Center (Minutes)

$\begin{array}{rcc}\text { Average Wait } & 0-25 & 25+ \\ 0-5 \text { Min. } & 38 \% & 18 \% \\ \text { 6-10 Min. } & 50 & 55 \\ 17-15 \text { Min. } & \frac{12}{100 \%} & \frac{27}{100 \%} \\ & N=8 & N=11\end{array}$

